\title{
Therapeutic outcomes in a museum? "You don't get them by aiming for them". How a focus on arts participation promotes inclusion and wellbeing.
}

\author{
Abstract \\ Background \\ The three year 'Ways of Seeing' project was hosted by an award-winning museum and included \\ adults with long-term diagnoses associated with mental health and physical impairments. The \\ participants were involved throughout the project, preparing and curating artwork for a major public \\ exhibition. \\ Methods \\ Qualitative data were collected to explore meanings of the project from the perspective of \\ participants, the project manager and the public, using interviews, participant observation and \\ comment cards. \\ Results \\ The project was successful in engaging the participants who had previously often felt excluded from \\ mainstream art spaces. Findings about the benefits of arts participation echoed other studies but \\ participants highlighted some difficulty with the ending of the project. Public perceptions were \\ positive, acclaiming the thought-provoking quality of the exhibition. Interviews and participant \\ observation revealed the importance of egalitarian leadership, mutual trust and the absence of any \\ therapeutic agenda.

\section{Conclusion} \\ Developing similar projects would offer opportunities to foster diverse artistic communities and \\ empower people with experiences of disability and mental health conditions.
}

\section{Background}

This paper reports on the evolution and development of a three year community arts project, 'Ways of Seeing' which was based in the Lightbox, a public museum and art gallery in Woking, United Kingdom. The project was well publicised and is named here with the full agreement of the museum staff and participants. It was initiated by the museum director and staff and funded by the Heritage Lottery Fund. Local people who took part were long-term users of mental health services with diagnoses such as schizophrenia, bipolar disorder and in some cases, physical and psychological impairments resulting from head injury. During the project they took part in introductory gallery visits; taster workshops followed by more in-depth art techniques (painting, drawing, print-making, sculpture); selected items from the large privately owned Ingram art collection housed within the Museum, and created their own responses to these items. It resulted in a successful major art exhibition. The impact of the project was explored independently by a research team of occupational therapists and a health psychologist from Brunel University London.

Museums and art galleries in the United Kingdom aim to engage with local communities to promote participation in the arts (Arts Council England, 2013). More recently this has included people not usually represented by the visiting public (Sendell \& Nightingale, 2012). People with long term mental health or physical problems have usually engaged with the arts from the perspective of a hospital or health environment, under the auspices of medical staff or therapists (e.g. Heenan, 2006; Spandler et al., 2007; Symons et al., 2011). Even in the community, arts projects are typically conducted with some specific therapeutic aims in mind (Hacking et al., 2008). Museums and art 
galleries, as spaces away from the clinical environment, have a pivotal role to play in the public health agenda, both in maintaining health and facilitating recovery (Colbert e al., 2013; Sagan, 2012; Stuckey \& Nobel, 2010), key objectives of current mental health strategy (Department of Health, 2011). The public health potential of the heritage sector is a hugely underestimated resource internationally (Camic \& Chatterjee, 2013).

However, there are particular challenges for the inclusion of people with long term health problems in public spaces, not only the stigma that attaches to mental health conditions (Lamb, 2009), but also practical barriers, such as physical accessibility, social attitudes and specific individual needs (Beresford, 2013; Taylor, 2009). These are the very barriers that have to be addressed in order to promote participation in the arts and prevent the perpetuation of social exclusion. Being excluded and socially isolated is known to have detrimental effects on health and recovery (Stickley, 2010, Sayce 2000). Overcoming the barriers requires practical problem solving in everyday practice as well as strategic attention to enabling access as required by law (Mandelstam, 2008). Adapting and designing the built environment to be more inclusive for disabled people is well advanced (Swain et al., 2014). Understanding how the social and occupational environment can be adapted is more subtle and is often developed through education to raise awareness of diverse needs and is therefore less tangible. It can be challenging but is best facilitated by the active involvement of disabled people themselves (Barnes \& Mercer, 2010).

The emphasis of the 'Ways of Seeing' project reflected the museum's interest in and commitment to overcoming these barriers and enabling inclusive participation in the arts. It was not initiated by local health or social care services, but rather, acknowledged existing partnerships with local organisations which was reflected in the membership of a steering group established at the beginning of this project.

The Lightbox is an award-winning museum, housing a local history exhibition as well as touring major art exhibitions. The local history includes displays with artefacts from the county asylum which has now closed. Oral histories were originally collected from local people, starting an ongoing partnership with those who had lived and worked in the asylum (Craze 2014). The Lightbox also has the Ingram Modern Art collection, which is on permanent loan and exhibited regularly. Pieces include those by Henry Moore, Picasso, Elisabeth Frink and other major artists. Since the Lightbox opened in 2007 it has had a stated intention to promote local community involvement, successfully obtaining external funding to support this work. 'Ways of Seeing' was the most ambitious project to date, aiming to exhibit selected work from the Ingram collection alongside art created by project members in response to the selected pieces.

The project was designed and led by a project manager with the support of the steering group, formed of members from local mental health support organisations and service users alongside the university research team. The goals identified at the beginning of the project in the funding application guided its development. There had been requests from people involved in local mental health arts projects to be involved in the museum's programmes and this project aimed to create such an opportunity for them. It was believed that participation by people with mental health problems could promote engagement and social inclusion, potentially as a route to paid employment. Another goal was to provide the museum staff and volunteers with training and skills for working with people with mental health problems.

In line with these goals, the overall aim of the research was to investigate and analyse the experiences of those people involved in the project in order to gain some understanding of the meanings of the process to its various participants. The importance of systematically evaluating the project was emphasised as a key requirement by the Heritage Lottery Fund and the project manager 
delegated the design and implementation of the data collection to the research team. Inevitably there is a tension in reporting research findings alongside the requirements of a formal evaluation but it is hoped that this paper will shed light on the processes involved and possibly provide a basis for guiding similar projects in the future.

\section{Methods}

A case study approach was undertaken to investigate the 'Ways of Seeing' project, drawing upon multiple data sources, with attention to context and developmental processes (Stake, 2008). The formal evaluation necessarily involved varied methods to meet the requirements of the funders and the museum. The funders required numerical data which indicated certain basic measurable outcomes of the project, so from the outset records were kept of who and how many people attended and when.

In order to meet the overall research aim, a more varied qualitative approach was adopted by the research team, while recognising that the epistemological assumptions of the researchers required a reflexive stance (Finlay, 2006) since they were primarily concerned with exploring the experiences of the project's participants (Smith, 2008). These experiences were examined as individual narratives and collective processes (Martin, 2011) together with the artistic outcomes of the project.

To complement these ongoing processes, the research team used an ethnographic approach to explore the participants' experiences of the project in more depth, seeking insights into the nature of those experiences and the cultural phenomena surrounding them (Reeves et al., 2008). In particular, the importance of listening to their voices, seeing the created art work and being present during the making of the art was felt to be paramount in capturing diverse experiences.

This approach to research emphasises the value of qualitative data for investigating experiences, generating knowledge about processes over and above outcomes captured in demographic and attendance data (Tonkiss, 2004; Pope et al., 2000). A social constructionist philosophy was adopted, acknowledging the interpretative lenses of the various researchers, and emphasising therefore the need for reflexivity throughout the project (Ashworth, 2008).

Gathering data which could be drawn directly from the setting (observing sessions, public comments cards) was considered to be a valuable and pragmatic means of enriching and confirming and potentially challenging findings from one-to-one interviews with the project manager and participants (Silverman, 2013). User involvement in the research was considered essential, recognising that individual participants could offer their perspectives in a variety of ways (Beresford, 2013).

Participant observations during the different phases of the project were recorded in fieldnotes by the first author, using an approach that involved short note-taking in situ followed by expanded notes after each observation session (Miles \& Huberman, 1994). These notes, artefacts, photographs and a reflexive diary were discussed regularly with the lead researcher in order to elaborate and challenge emerging understandings. From when participants began to make their own artworks, three in-depth interviews were conducted with the project manager to capture different phases of the project. These interviews were transcribed verbatim and analysed thematically. When the exhibition was over, the comments cards from the visiting public were catalogued using a spreadsheet and content analysis was applied to the data to enable categories of similar comments and their frequency to emerge (Neuendorf, 2002). This data collection method provided an accessible, convenient way of capturing the experiences of large numbers of visitors with minimal 
influence. Comments cards are also thought to offer the potential of inviting more private, critical comments than some alternatives such as open visitors books (Caldwell, 2005). They also offered a means of inviting visitors to think deeply about disability and mental health, thereby engaging with an unusual aspect of the exhibition (Dodd et al., 2010).

An MSc occupational therapy student undertook separate interviews of participants about their experiences half-way through the project (reported separately in Lawson et al., 2014) and a video artist captured the whole project in film. These different sources of data, which were integrated into the project from the beginning, informed the detailed account and analysis of the project for the funder's final evaluation report (Bryant, Wilson \& Lawson, 2011).

Reflexivity was an important part of the process and the research team met regularly during the project to discuss and reflect on the influence of individuals' social background, assumptions and positioning on the research process (Finlay and Gough 2003). In particular, during the data analysis phase, frequent checking of the emerging themes and auditing the raw data increased its robustness trustworthiness (Mays \& Pope).

Ethical approval was obtained from Brunel University Ethics Committee; especially, issues of informed consent were pertinent to this study as well as ethical considerations associated with using photographs of people and artwork for academic purposes, and naming the host museum.

\section{Results}

The findings of our research have been organised here into a short narrative, an alternative brief overview based on facts and figures, followed by the perspectives of participants, the project manager and the public. All these findings suggest that 'Ways of Seeing' was considered to be a success, overcoming challenges during its three years of existence and engaging people in many different ways to achieve the project aims.

\section{'Ways of Seeing'}

To launch the project, people who self-identified themselves as living with mental health problems (and in some cases physical disabilities) were invited to join via information leaflets, poster advertisements and word of mouth in the local area using existing mental health organisations. (Initial attempts to recruit for the whole project resulted in a very poor response. However, once the steering group suggested a staged approach, linking recruitment to the different phases of the project without the pressure of a long-term commitment, the numbers of interested participants increased substantially. A summary of the number of people involved, and other quantitative data, is presented in Table 1. 
Table 1: 'Ways of Seeing' summary of quantitative data

\begin{tabular}{|l|l|}
\hline Key figures & $f 50,000$ \\
\hline Funding from Heritage Lottery Fund & 3 years \\
\hline Duration of project & 10 weeks \\
\hline Duration of exhibition & 29 \\
\hline Number of participants involved overall & 17 \\
\hline Number of participants involved for more than one phase & 9 \\
\hline Number of participants involved from beginning to end & 4 \\
\hline Number of workshop leaders/artists employed & $100 \%$ staff, 15\% \\
\hline Proportion of gallery staff and volunteers involved & volunteers \\
\hline Number of people visiting the exhibition & 6530 \\
\hline Number of comments cards left by the public & 148 \\
\hline Number of people who attended the symposium & 54 plus speakers \\
\hline
\end{tabular}

Based on an appraisal of what participants might need to know and understand, at each phase the project was carefully planned to allow the different facets to emerge. Initially participants were oriented to how visual art is created and exhibited, with a series of visits to artists' studios and workshops about major art collections. Museum staff contributed sessions to discuss and contextualise what participants had observed on the visits. This phase successfully attracted a number of people and was followed by taster workshops of different art techniques, which took place once a week at the museum (painting, drawing, printmaking and sculpture).

These phases of the project aimed to give participants knowledge, skills and understanding to equip them for the decisions required in the next phase. Every item in the Ingram Collection was brought up from the store so participants could examine and agree a selection to inspire their own artistic responses, again meeting once a week over seven months. They created their responses in all-day workshops; covering the same techniques as before and giving everyone space and time to get started. Curation of the exhibition gathered pace as participants worked together to make final selections of their own artistic responses and items from the Ingram Collection. The ensuing exhibition offered opportunities for everyone to have some of their work exhibited to the public alongside the selected work from the Ingram Collection. A symposium halfway through the ten week exhibition which included the participants brought together interested people from throughout the UK, sharing experiences of engaging the public in active ways to promote their health and wellbeing. The end of the exhibition was marked with a community cabaret performance before it was taken down. The people involved had remarkable experiences over the three years, choosing how to take part in each phase leading up to the exhibition, making all the decisions about what was to be included and how the work was displayed. 


\section{Participant Experiences}

The experiences of eight of the participants were captured as part of an MSc occupational therapy research project by means of individual semi-structured, in-depth interviews which were subject to interpretative phenomenological analysis (IPA), an in-depth analytical approach which focuses on both common and individual meanings of a shared experience (Smith et al., 2009). In summary, seven overarching themes emerged, framed in the participants' own words, following IPA tradition: 'I wouldn't have missed it for the world'; 'There are things I can still do'; 'Working within the group'; 'You are treated like a human being'; 'It was like a history lesson and art lesson at the same time'; 'It's having a focus'; 'It's not all glamorous'.

These validate some of the findings from previous research highlighting the benefits of arts participation. However, they also throw some light on the negative aspects of community-based arts, particularly in relation to endings, which are rarely addressed in the literature.

The full research process and findings from this part of the project have been published elsewhere (Lawson et al., 2014).

\section{Perspective of the Project Manager}

The innovative nature of 'Ways of Seeing' project prompted interest into how leadership underpinned the project's success. The project manager's experiences were recorded from direct observations during the project and three in-depth interviews. Thematic analysis indicated important elements of his approach, based on his constant presence, not seeing the project as therapy, and taking a phased, flexible approach which gave scope for negotiating decisions among the participants. These themes are examined briefly here.

\section{Constant presence}

The project manager was invited to lead the project based on seven years' involvement with previous local arts projects such as community plays, meaning that he was known locally. He welcomed the opportunity:

'I was very lucky, the organisation was up for it. They had a fantastic art collection on loan.'

This was the first local project aiming directly to involve people with mental health problems in interpreting works of art and creating new ways of looking at those works, including curating the exhibition. The project manager had been surprised when asked to manage this particular project, not having a background in visual art nor extensive experience of working with people who have mental health problems:

'But I felt a little odd about even being asked about it because it was about visual art and mental health and I'm not a visual artist and I don't know that much about mental health!'

However, it was his ability to co-ordinate the project unobtrusively but purposefully with a combination of sensitive leadership and facilitation that was key to its success. This was observed during the project and commented on in conversation with the participants. He saw this in terms of his commitment to the project:

'Well, there's two things - one that's important for this sort of project is a constant presence. Anyone could do it, but the point was, I was always there.' 
This presence was not in terms of being physically present, or micro-managing activities, but holding the vision of the final exhibition and keeping it present in everyone's awareness:

'That's why they took me on presumably - it reminded me much more of a community play and community plays will quite often last a couple of years.'

The project manager's constant and consistent presence was very important to the participants, even though he described himself as the 'tea boy' during the workshops. It was observed that he fetched lunch and made sure everyone had access to refreshments on every occasion that they met. He thought that everyone knew that if there were any problems, he would be able to make a helpful response. This practical approach sustained progress to the exhibition and also gave him detailed knowledge of the participants so that differences of opinion could be overcome in the most appropriate way for them as individuals.

\section{Not therapy}

A typical individualised approach to working with people reflects how health and social care professionals engage and enable their service users to meet goals, as therapy or rehabilitation. But the project manager was very keen to stress that the project was not set up as a therapeutic endeavour:

'And the other [strength] is about it not being therapy - I'm not a trained therapist and we had no intention of employing a therapist and we don't run classes here. The way to do it was to have those people feel genuinely that they were contributing to the life of this place and putting together an exhibition.'

The end-point of the public exhibition drove a serious exploration and interpretation of the art encountered and created:

'They weren't there to have their mental health problems dealt with, they were there to work on the art, to learn about art, to learn about the collection and the skills to be able to respond to it.'

Nevertheless, he noted that there were definite therapeutic benefits for some, attributed partly to the acceptance and respect from Lightbox staff as well as being part of such a purposeful project over time:

I'm sure that it has therapeutic effects. And they're by the by, well not quite by the by, but byproducts that we knew would happen, I certainly hoped would happen - but you don't get them by aiming for them.'

The emphasis was on the shared experience of arts participation, rather than contrasting with how health and social care services are required to focus on individual problems and strengths to deliver targeted person-centred care. The final exhibition as a goal did not override individual ways of participating but provided direction. The idea that therapeutic outcomes could be achieved in this way challenges current thinking about health and wellbeing, which is often symptom-focused.

\section{Phased and flexible approach}

Initially starting with a launch event, recruitment for the project did not go very well:

'We had a launch event - which didn't go well at all - we had more staff there than anyone else and that was the criticism.' 
It was realised that to invite people to be part of the whole project was too daunting. This was changed to inviting people to take part one phase at a time, which worked much better. From then on, some people were involved throughout and more people were recruited, mostly through word of mouth:

'By seeing people week after week and then we invited them to be part of this project, they knew who we were and also they were comfortable in the building.'

By the end of the project, after three years of establishing its different phases and building up the infrastructure, the project manager described the resulting exhibition as being 'hugely successful.'

Working alongside, some participants were involved throughout. There were challenges during the different phases. To ensure everyone was included in a way that worked for them, different approaches were required, some of which involved problem solving on the spot and some required reflection with the steering group members. There were conflicts at times, especially when difficult decisions had to be made about inclusion and exclusion and the project manager was aware that it was not possible to please everyone all of the time:

'Well, yes, but the process was not perfect, so we'll leave it at that.'

Where possible, he worked to include people in decision-making, so they could negotiate and understand the final outcomes. He questioned his own decisions, for example when engaging artists to lead the workshops:

'There's a trade-off between the democratic and the group functioning but on other issues I'd like to have given them even more choice, if possible. I would have got participants to choose fairly early on which workshop leaders they wanted to employ.'

This self-questioning, or reflective, style of leadership strengthened the project's flexibility. His democratic style and non-judgemental way of being greatly contributed to the overall achievements of everyone involved in the project. He attributed this to the support of the steering group and Lightbox staff. However, he clearly sustained the vision of enabling the participants to reach the goal of putting on an exhibition and the outcome exceeded all expectations. The success of the project was evident in the comments from people attending the 'Ways of Seeing' exhibition, once it was opened to the public.

\section{Views of the Public}

The responses from the 148 public comment cards were positive and varied. It became clear that visitors understood the importance of including diverse artwork, and welcomed the varied responses to the original artwork from the Ingram Collection.

Four interconnecting themes emerged from the content analysis of the written comments: with 'Enjoyment and appreciation'; 'Seeing in a different way'; 'Shared experiences' and 'Local pride' all being closely associated with an understanding of what the exhibition had achieved. In each theme, the number of comments relating to that theme was also recorded.

\section{Enjoyment and appreciation}


The highest number of comments expressed enjoyment which was about the aesthetics of the artwork as well as appreciating the aims of the exhibition:

'I love this project - the variety, quality and freedom of it. I've been 3 times and every time I see something new and inspiring. It's a rich experience.'

'The way the pieces were put together was very helpful for understanding the connection between them.'

\section{Seeing in a different way}

Many visitors found the exhibition inspiring and thought-provoking and were inspired by the talent evident in the artwork:

'Wonderful and thought provoking exhibition helps us all stop for a minute and think about our world differently.'

'Hugely impressive. I was amazed by the raw talent of the participants. There's hope for all of us.'

\section{Shared experiences}

The relationship between the original artworks and the participants' responses was a focus for some comments:

'This project seems to have revealed something in the artists. The breath of execution is staggering and the way of exhibiting is so good. They are such intimate responses - a revelation.'

Other visitors described being able to understand and appreciate the responses to the original artwork. This enabled some to gain insight into experiences of mental health issues:

'Gives an inner "look" into the minds of people with mental health problems - same as everyone! Just a wonderful exhibition.'

\section{Local pride}

An unexpected finding was the expression of local pride, validating the vision of the Lightbox to include local people and the participants' achievements:

'Woking is fortunate to have such a wonderful art gallery.'

'Thanks again to Chris Ingram who lifts Woking.'

Although the privacy in which cards are completed and submitted permits a critical response (Caldwell, 2005), there was an absence of negative responses, which could have been due to a desire to show respect for those involved, given the sensitive nature of mental health issues. The comments were anonymous and unsolicited and the actual number of comments made was unprecedented for any exhibition at the Lightbox, showing the strength of positive public reaction.

\section{Discussion}


The findings have illustrated how a public art gallery or museum can engage people in an inclusive and ambitious way. This echoes and develops findings by other researchers, e.g. Hacking et al., (2006); Secker et al., (2007); Roberts et al., (2011); Colbert et al., (2013).

Three further inter-connected aspects highlighted by this project and that draw the findings together are discussed here: authenticity, having high quality resources and community art as a transformative experience.

The commitment to a vision for 'Ways of Seeing' made experience of the project authentic, from many different perspectives. This authenticity was enhanced by the project being very wellresourced from the start and given serious backing. The project could also make good use of the resources available to it, especially the human ones. This engaged individuals and the community as a whole in a developmental process. However, in terms of individual development, there was resistance to seeing the changes in therapeutic terms as the purpose of the project. This raises interesting questions about the emphasis of community arts projects when used to promote health and wellbeing.

The 'Ways of Seeing' project was authentic, meaning that it offered a genuine real-world experience of creativity, ownership and decision-making. The guiding vision was constant and consistent, giving committed focus to the associated tasks and activities. People had opportunities to impact on the life of the museum, becoming part of the museum itself. The project was firmly situated in the arts world rather than the clinic, or health services, an important aspect highlighted by the work of Sagan, (2012). By being located in the Lightbox museum, choices for people about how they participated were real and included the public visitors who perceived these choices, expressed in the exhibition. The Ingram Collection consists of high quality and recognisable artwork which gave further significance and authenticity, by giving direct and hands-on access to people who might otherwise be stigmatised as unreliable, antisocial or otherwise socially excluded. By having such close access to priceless and prized objects and having their own work valued by the public gave a strong message of acceptance in the local community and challenged previously held assumptions (Lawson et al., 2014). Previous research has shown that being trusted with heritage items increases well-being (Thomson et al., 2012). The emphasis on being taken seriously as artists provided an authentic experience away from the illness narrative, giving the participants a genuine sense of being valued.

These notions of authenticity combine understandings from the arts and from health and social care, valuing the context for creative activity as much as the end product. Creative activity is valued in health and social care as a means of achieving varied goals for individuals (Walters et al., 2014), but can be compromised by limited resources and might be devalued if seen as filling time or keeping people busy. In contrast, the art produced by people with mental health problems is recognised as being valuable, as promoted by the Outsider Art movement (Maizel, 2009), but there can still be a focus on people's diagnoses or problems.

This project gave people genuine choice about how to bring the different elements of their experiences together, so that the authenticity of their work was embedded in the overarching vision of different ways of seeing, rather than an emphasis on expressing and resolving health problems. The leadership recognised the capacity for all involved to make mistakes and also the significance of individual and collective reflection by questioning and agreeing decisions along the way.

This way of thinking about participation, considering the purpose, the context and individual circumstances, is increasingly important in mental health services promoting recovery (Lloyd et al., 
2007; Secker et al., 2007; Colbert et al., 2013). The context, the Lightbox, was different from projects within mental health services. Being involved in projects like this has been seen as "stabilising" (Parr, 2009): it is not just doing art-based activities, but having a sense of belonging to associated high quality public areas such as the café and gallery itself. In addition to the artistic focus of the project, the social opportunities enabled people to take on different roles and identities. This has been recognised as a benefit of arts participation by many researchers including Lloyd et al., (2007), Spandler et al., (2007) and Van Lith et al., (2013).

The use of artwork from the Ingram Collection engaged participants and the public in a high quality aesthetic experience. Using resources in this way, to widen participation and foster community involvement, effectively changes attitudes and promotes social integration (Lamb, 2009). Sharing and reflecting on the different ways of responding was thought-provoking for participants and public alike, challenging assumptions about disability, modern art and participation in the arts. There was curiosity and novelty - could new interpretations and understandings be revealed? This has also been suggested by the idea of 'outsider' art history, where people with expertise not related to art history offer a new perspective on a visual image (Gotlieb, 2008). Inspirations extended beyond the artwork to participants' lives as a whole, with some making major changes in their lives (Lawson et al., 2014), supporting the idea that enabled participation is often a 'stepping stone' to other things (Heenan, 2006).

This project was well resourced, occurring just before austerity measures impacted on so many aspects of community life. Yet it is worth capturing what could be achieved with sufficient resources. The investment in leadership was not just about securing a project manager with appropriate values and experience, but also enabling a long-term commitment over three years to see the project through. The funding also enabled the contribution of practising artists and the professional standard of the final exhibition. This meant the exhibition could take place in a central gallery space rather than being marginalised in a more peripheral location, with less publicity.

Other resources were less dependent on the funding, being embedded in the attitudes and values that underpinned the project, manifested by skilled leadership. The drawback to having such funding was the pressure to demonstrate outcomes, based on goals that were set prior to the project's inception and an expectation of quantitative outcome measures, despite many of the benefits being intangible or difficult to separate out.

Making the project accessible to people with varied and complex needs involved responding in a practical and empathic way at every phase of the project (Beresford, 2013). For example, providing mental health awareness training for the museum staff proved most valuable. Taylor (2009) has suggested that addressing accessibility issues for people with mental health problems can be as simple as identifying a barrier, understanding why it is a barrier, and removing it. Despite apparent barriers, people are attracted to opportunities which are novel, based on activity and responsive to their needs (Culbard, 2009) and community arts projects such as 'Ways of Seeing' are important and valuable in this respect.

This approach resists prescribing arts activities as therapy for specific individual health problems. A health promotion element became apparent, recognising that positive change can apply equally to communities as individuals (Stuckey \& Nobel, 2010). This has a profoundly political basis, recognising how participation can indicate citizenship, increasing social appreciation of human diversity and potential.

The idea of sharing different perspectives on major art works, to engage the public with visual arts, has evolved with the work of Berger et al., (1972), who suggested that sharing interpretations challenges the assumptions that people hold. This could be about the art works or, on a more 
general level, about being a visitor to museums and galleries. Sharing perspectives and interpretations can happen at any point in visiting, highlighting the importance of everyone, at every level of an organisation, being responsible for promoting inclusion (Culbard, 2009). Inclusion is not just about increasing diversity of visitor profiles, however, but about increasing social links or networks between people. Reciprocal social links are fundamentally important for health (Wilkinson, 2005) as highlighted by the views of the public.

\section{Limitations}

Whilst case study research is very suited to exploring the complexity of 'actual practices' and 'backstage social phenomena' (Flyvbjerg, 2011, p.312), clearly there are limitations to a project such as this. Case studies use multiple methods and hence present challenges in managing and interpreting (with credibility and transparency) the large volume of data collected. Having several members within the research team, and a reflexive attitude enabled multiple interpretations of the qualitative data. Yet despite a search for negative instances, few were located (apart from some of the participants' concerns with the ending of the project). Case studies are essentially contextspecific, generalisation is not a straightforward matter, and it is difficult to identify how the manager, arts facilitators, local socio-economic environment and indeed the participants themselves influenced the success of the project. Apart from some negative perceptions of the ending of the project (Lawson et al 2014), very few problems were identified. We have suggested that this reflects an ongoing willingness to be flexible and adapt processes as the project evolved. Nonetheless, further enquiry could be conducted to explore why some participants discontinued involvement part-way through the three years, and how the project provided some but not all with 'stepping stones' to future meaningful occupations

\section{Conclusion}

The philosophy behind this project was a willingness to take an interest in the participants as people rather than as people defined as having mental health or physical problems and not to enquire into any changes in their use of health or social care support services. Therefore there was no 'hidden agenda' about reducing the need for health care services, but rather a recognition that creating opportunities for arts participation in a high quality museum setting resulted in an improvement in participants' quality of life by promoting acceptance, belonging and citizenship. Genuine belonging and 'prizing' were further reinforced by public perceptions, as gathered from visitors attending the final exhibition.

\section{References}

Arts Council England. (2013). Great art and culture for everyone: 10 year strategic framework. $2^{\text {nd }}$ Edition. Manchester: Arts Council England.

Ashford, P. (2008). Conceptual foundations of qualitative psychology. In Smith, J.A. (Ed.), Qualitative psychology: A practical guide to research methods. Thousand Oak, CA; Sage (pp4-25). 
Barnes, C., \& Mercer, G. (2010). Exploring disability. 2nd Edition. Cambridge: Palgrave.

Beresford, P. (2013). Beyond the usual suspects - towards inclusive user involvement. London: Shaping our Lives.

Berger, J., Blomberg, S., Fox, C., Dibb, M., \& Hollis, R. (1972). Ways of Seeing. London: Penguin Books Ltd.

Bryant, W., Wilson, L., \& Lawson, J. (2011). 'Ways of Seeing' Evaluation. London: Brunel University.

Caldwell, N. (2005). The Whipple 'Time-clock' Experiment: Measurement of visitor engagement in a small museum. Available from: http://neumann.hec.ca/aimac2005/PDF Text/Caldwell Nial.pdf

Camic, P.M., \& Chatterjee, H. J. (2013). Museums and galleries as partners for public health interventions. Perspectives in Public Health, 133, 66-71. DOI: 10.1177/17579132468523

Colbert, S.M., Cooke, A., Camic, P.M., \& Springham, N. (2013). The art-gallery as a resource for recovery for people who have experienced psychosis. The Arts in Psychotherapy, 40, 250-256. DOI: 10.1016/j.aip.2013.03.003

Craze, A. (2014). From asylum to community care. A history of Brookwood Hospital told by those who worked and lived there. Guildford: Alison Craze.

Culbard, K. (2009). Exploring access. Engage: International Journal of Visual Art and Gallery Education, 23, 39-44. DOI: No number available. ISSN1365-9383.

http://www.engage.org/seebook.aspx?id=2426

Department of Health. (2011). No health without mental health: A cross-government mental health outcomes strategy for people of all ages. London: Mental Health and Disability, Department of Health.

Dodd, J., Jones, C., Jolly, D., \& Sandell, R. (2010). Disability reframed: Challenging visitor perceptions in the museum. In Sandell, R., Dodd, J., Garland-Thomson, R. (Eds.), Re-presenting disability: Activism and agency in the museum. Abingdon: Routledge.

Finlay, L. (2006). Mapping Methodology. In: Finlay, L., \& Ballinger, C., (Eds.), Qualitative research for allied health professionals: Challenging choices. West Sussex: Whurr.

Finlay, L., \& Gough, B. (Eds.) (2003). Reflexivity: A practical guide for researchers in health and social sciences. Oxford: Blackwell.

Flyvbjerg, B. (2011). Case study. In N. Denzin and Y. Lincoln (Eds.), The Sage handbook of qualitative research (pp.310-316). Thousand Oaks, CA: Sage.

Gotlieb, M. (2008). Our monstrous double: the dream of research in 'Outsider Art History'. In Holly M. \& Smith M. (eds.), What is research in the visual arts? Obsession, archive, encounter. New Haven: Yale University Press. 
Hacking, S., Secker, J., Spandler, H., Kent, L., \& Shenton, J. (2008). Evaluating the impact of participatory arts projects for people with mental health needs. Health and Social Care in the Community, 16, 638-648. DOI: 10.1111/j.1365-2524.2008.00789

Heenan, D. (2006). Art as therapy: an effective way of promoting positive mental health? Disability and Society, 21, 179-191. DOI: 10.1080/09687590500498143

Lamb, J. (2009). Creating change: Using the arts to help stop the stigma of mental illness and foster social integration. Journal of Holistic Nursing, 27, 57-65. DOI: 10.1177/0898010108323011

Lawson, J., Reynolds, F., Bryant, W., \& Wilson, L. (2014). 'It's like having a day of freedom, a day off from being ill': Exploring the experiences of people living with mental health problems who attend a community-based arts project, using interpretative phenomenological analysis. Journal of Health Psychology, 19, 765-777. DOI: 10.1177/1359105313479631

Lloyd, C., Wong, S.R., \& Petchkovsky, L. (2007). Art and recovery in mental health: a qualitative investigation. British Journal of Occupational Therapy, 70, 207-14.

DOI: $10.1177 / 030802260707000505$

Maizel, J. (ed.). (2009). Outsider art sourcebook. Radlett: Raw Vision Ltd.

Mandelstam, M. (2008). Community care practice and the law. $4^{\text {th }}$ edition. London: Jessica Kingsley.

Martin, V. (2011). Developing a narrative approach to healthcare research. Abingdon: Radcliffe.

Mays, N., \& Pope, C. (2000). Qualitative research in health care: Assessing quality in qualitative research. British Medical Journal, 320:50-52. DOI: 10.1136/bmj.320.7226.50

Miles, M. \& Huberman, A. (1994). Qualitative data analysis: An expanded sourcebook. Thousand Oaks: Sage.

Neuendorf, K. A. (2002). The content analysis guidebook. Thousand Oaks, Ca: Sage.

Office of the Deputy Prime Minister. (2004). Mental health and social exclusion. London: Office of the Deputy Prime Minister. http://www.communities.gov.uk/publications/corporate/mentalhealth

Parr, H. (2009). Mental health and social space. Oxford: Blackwell Publishing.

Pope, C., Ziebland, S., Mays, N. (2000). Qualitative research in health care: Analysing qualitative data. British Medical Journal, 320:114-16. DOI: 10.1136/bmj.320.7227.114

Reeves, S., Kuper, A., \& Hodges, D. (2008). Qualitative research methodologies: Ethnography. BMJ, 337: a1020. DOI: 10.1136/bmj.a1020

Roberts, A., Camic, P.M. \& Springham, N. (2011). New roles for art galleries: Art viewing as community intervention for family carers of people with mental health problems. Arts \& Health: An International Journal for Research Policy and Practice. 3, 146-159.

DOI: $10.1080 / 17533015.2011 .561360$

Sagan, O., (2012). Connections and reparation: Narratives of art practice in the lives of mental health service users. Counselling Psychology Quarterly, 25, 239-249. DOI: 10.1080/09515070.2012.703128 
Sayce, L. (2000). From psychiatric patient to citizen. London: Palgrave MacMillan

Secker, J., Hacking, S., Kent, L., Shenton, J., \& Spandler, H. (2007). Empowerment and arts participation for people with mental health needs. Journal of Public Mental Health, 6, 14-23. DOI: 1108/17465729200700024

Sendell, R., \& Nightingale, E. (Eds.) (2012). Museums, equality and social justice. London: Routledge. Silverman, D. (2013). Doing qualitative research: A practical handbook. Fourth Edition. London: Sage. Smith, J.A. (Ed.) (2008). Qualitative psychology: A practical guide to research methods. $2^{\text {nd }}$ Edition. London: Sage.

Smith, J.A., Flowers, P., \& Larkin, M. (2009). Interpretative phenomenological analysis: Theory, method and research. London: Sage.

Spandler, H., Secker, J., Kent, L., Hacking, S. \& Shenton, J. (2007). Catching life: The contribution of arts initiatives to recovery approaches in mental health. Journal of Psychiatric and Mental Health Nursing, 14, 791-799. DOI: 10.1111/j.1365-2850.2007.01174

Stake, R. (2008). Qualitative case studies. In Denzin N., and Lincoln, Y. (Eds.). Strategies of qualitative inquiry (pp.119-150). Thousand Oaks, CA: Sage.

Stickley, T. (2010). Does prescribing participation in arts help to promote recovery for mental health clients? Nursing Times, 106, 18-20. DOI: No number available. http://www.nursingtimes.net/nursing-practice/specialisms/mental-health/does-prescribingparticipation-in-arts-help-to-promote-recovery-for-mental-health-clients/5014509.article

Stuckey, H.L., \& Nobel, L. (2010). The connection between art, healing and public health: A review of current literature. American Journal of Public Health, 100, 254-263. DOI: 10.2105/AJPH.2008.156497

Swain, J., French, S., Barnes, C., \& Thomas, C. (Eds.) (2014). Disabling barriers - Enabling environments. $3^{\text {rd }}$ edition, London: Sage.

Symons, J., Clark, H., Williams, K., Hansen, E., \& Orpin, P. (2011). Visual art in physical rehabilitation: Experiences of people with neurological conditions. The British Journal of Occupational Therapy, 74, 44-52. DOI: 10.4276/030802211X12947686093729

Taylor, M. (2009). Disability and the visual arts. Engage: International Journal of Visual Art and Gallery Education, 23, 8-15. DOI: No number available. ISSN1365-9383.

http://www.engage.org/seebook.aspx?id=2424

Tonkiss, F. (2004). Analysing text and speech: content and discourse analysis. In: Seale, C. Researching society and culture. Second Edition. Sage publications, pp 368-82.

Thomson, L. J., Ander, E. E., Menon, U., Lanceley, A., \& Chatterjee, H. J. (2012). Quantitative evidence for wellbeing benefits from a heritage-in-health intervention with hospital patients. International Journal of Art Therapy, 17, 63-79. DOI: 10.1080/17454832.2012.687750

Van Lith, T., Schofield, M. J., \& Fenner, P. (2013). Identifying the evidence-base for art-based practices and their potential benefit for mental health recovery: A critical review. Disability and Rehabilitation, 35, 1309-1323. DOI: 10.3109/09638288.2012.732188 
Walters, J., Sherwood, W., Mason, H. (2014). Creative activities. In Bryant, W., Fieldhouse, J., Bannigan, K. (eds.), Creek's occupational therapy and mental health. Oxford: Elsevier.

Wilkinson, R. (2005). The impact of inequality. How to make sick societies healthier. London: Routledge. 